\title{
Local Distortions in Nanostructured Ferroelectric Ceramics through Strain Tuning
}

Gilles Philippot, Marjorie Albino, Romain Epherre, Geoffroy Chevallier, Yannick Beynet, Charles Manière , Alicia Weibel , Alain Peigney, Marco Deluca, Catherine Elissalde, *Mario Maglione, Cyril Aymonier , and Claude Estournès

Ferroelectric materials are highly sensitive to grain size reduction because strain and ferroelectric polarization have a direct connection. Using $15 \mathrm{~nm}$ (Ba,Sr)TiO 3 particles obtained by advanced supercritical synthesis and their densifi cation by high-pressure spark plasma sintering under air, reproducible and dense nanostructured ceramics are achieved. Taking advantage of the high pressure (up to $600 \mathrm{MPa}$ ) applied during the sintering step, the internal stress generated at the grain scale can be monitored to compensate for the particle surface stress due to size effect. Both the local dynamics observed by Raman scattering and the overall dielectric behavior consistently indicate a recovery of the ferroelectric properties as the sintering pressure is increased. This unique behavior shows that low-temperature and high-pressure processing enables designing nanostructured functional ceramics exhibiting original properties.

\section{Introduction}

Several functional oxides exhibit properties highly sensitive to particle size. The stabilization of phases in polymorphic materials such as $\mathrm{ZrO}_{2}, \mathrm{Al}_{2} \mathrm{O}_{3}$, and $\mathrm{TiO}_{2}$ is modifi ed in nanopowders and unusual phases can be retained at the nanoscale. [1-5] The effect of strain and surface energies on the stabilization of metastable polymorphs has

been evidenced. Besides, because of the large coupling between spontaneous lattice strain and polarization, ferroelectric properties are dependent on grain size in ferroelectric ceramics. Below a critical grain size, which depends strongly on the processing conditions, a decrease of the tetragonal distortion and thus a stabilization of the cubic phase are observed. [ 6-11 ] Zhao et al. have provided new insights in size effect through a systematic investigation of crystal structure, phase transitions, and permittivity, performed on highly densifi ed nanocrystalline $\mathrm{BaTiO} 3$ ceramics $(50-1200 \mathrm{~nm})$ obtained using spark plasma sintering (SPS). [ 12 ] An additional contribution when referring to nanocrystals lies in the presence of hydroxyl defects, which can drastically affect the surface energy. [ 6,11,13-15] As a consequence, controlling composition, defects, particle size, and crystallinity is mandatory to master the dielectric properties. This represents a major issue to face the drastic expectations in the fi eld of ferroelectric ceramics for electronic applications. However, producing well-crystallized sub-50 nm grains of narrow size distribution over a whole solid solution and keeping such fi ne grain size within the fi nal ceramic is still challenging. Although the grain size effect in $\mathrm{BaTiO}_{3}$ has been largely reported in literature, only few studies are devoted to nanostructured barium strontium titanate

ceramics $\left(\mathrm{Ba}_{1} x \mathrm{Sr}_{x} \mathrm{TiO}_{3} 0 \delta x \delta\right.$ 1). [ 16-19] Both the synthesis route 
used to produce the initial particles and the shaping process are major steps to reach a reliable buildup of the nanostructured materials. We emphasize here the advantages of combining supercritical fl uid synthesis and spark plasma sintering to produce functional nanostructured ceramics. These fast processes allow an accurate control of size, chemistry, and crystallinity leading to an appropriate control of the properties at the nanoscale. The supercritical fl uid method offers continuous, scalable, fast, and facile routes toward well-crystallized tailormade oxide nanoparticles. The accurate control of size through the process operating parameters can give access to the critical size of nanostructures as exemplifi ed by crystalline $\mathrm{ZrO} 2$. [ 20 ] A critical particle size of 5-6 nm for monoclinic $\mathrm{ZrO} 2$ is obtained and either monoclinic or tetragonal zirconia phases can be obtained in the continuous supercritical reactor. Beyond size effects, this versatile technique also allows tuning materials crystallinity; this was demonstrated with the case of alumina by a simple modifi cation of the fl uid nature. Amorphous or boehmite alumina can be successfully obtained using $\mathrm{CO}_{2}$ /ethanol or $\mathrm{H}_{2} \mathrm{O}$ /ethanol, respectively. A signifi cant decrease of the (c)- $\mathrm{Al}_{2} \mathrm{O}_{3} \square\left\langle-\mathrm{Al}_{2} \mathrm{O}_{3}\right.$ transition temperature is obtained with the amorphous alumina resulting in a lower densifi cation temperature. [21] Amorphous but also highly crystalline nanostructures can be designed using the supercritical fl uid technology with the synthesis of exciton luminescent $\mathrm{ZnO}$ nanoparticles. [ 22 ] Furthermore, the control of the chemistry in supercritical fl uids

offers the possibility to master materials composition and the case of $\mathrm{BaTiO} 3$ based nanoparticles is a good example. [23 ] Nanopowders of the whole solid solution $\mathrm{Ba} 1{ }_{x} \mathrm{Sr}_{x} \mathrm{TiO}_{3}(0 \delta x \delta 1)$ are now easily accessible. [24,25] Besides, among the consolidation techniques, SPS is well recognized as a very effi cient tool to yield functional ceramics with controlled microstructures (i.e., low level of porosity and tailored grain size). [ 26,27 ] It has been clearly evidenced in literature that an applied pressure during sintering drastically enhances the densifi cation via sliding, rearrangement, or plastic deformation of the particles. This effect

combined with high heating rates achieved in fi eld-assisted sintering allows obtaining dense nanostructured ceramics. To illustrate this purpose, one can refer to the work of AnselmiTamburini et al. in which they developed a tool allowing high pressure up to $\mathrm{GPa}$. [ 28 ] They have been able to obtain from a cubic $\mathrm{ZrO} 2$ nanopowder (15 $\mathrm{nm}$ average grain size) dense ceramics (relative density, $D_{\mathrm{r}}=95 \%$ ) without grain growth compared to the initial powder.

We illustrate here that the association of high-pressure SPS under air with the continuous and controlled design of oxide particles by supercritical fl uids is a fast and fl exible approach toward the investigation of nanostructured ceramics made of barium strontium titanate (Ba $0.6 \mathrm{Sr} 0.4 \mathrm{TiO} 3$ or BST64) with grain size below $20 \mathrm{~nm}$. SPS sintering under air of nanostructured ceramics applying uniaxial pressures of several hundred of MPa was not yet reported in literature in the fi eld of ferroelectric materials. The previous investigations related to size effect and based on spark plasma sintering refer to powders with grain size larger than $50 \mathrm{~nm}$ and applied pressure in the range 50-100 MPa. We will emphasize here the particle size effect and the role of the external pressure applied during sintering on the short range order structure, which strongly impact the macroscopic properties.

\section{Results}

2.1. SPS Sintering and Microstructural Characterizations

Well-crystallized BST64 nanoparticles with an average size of 
$15 \mathrm{~nm}$ and a very narrow particle size distribution $(\square\} 2 \mathrm{~nm})$ were directly obtained after synthesis ( Figure 1 ). No additional calcination step was required prior sintering neither to improve the crystallinity nor to release undesirable barium carbonates. In order to fulfi 11 the expectations in terms of grain size control within the fi nal ceramic, the SPS temperature was maintained as low as $750{ }^{\circ} \mathrm{C}$ and the pressure was increased from 300 up to $600 \mathrm{MPa}$ in order to improve the densifi cation. Increasing the compressive stress applied during SPS up to several hundreds of MPa favors the elimination of agglomerates, enhances the densifi cation mechanisms, and activates mechanisms such as plastic deformation or grain boundary sliding at low temperature. As a result, homogeneous subsequent densifi cation without grain growth is promoted. Air atmosphere was selected to limit detrimental reduction of titanium arising when SPS is performed under low oxygen partial pressure atmosphere. [ 29,30] Increasing the pressure from 300 up to $400 \mathrm{MPa}$ raised density from $86 \%$ to $91 \%$ and a further pressure increase up to $600 \mathrm{MPa}$ did not lead to signifi cant improvement in density. High resolution scanning electron microscopy (HRSEM) analysis shows unambiguously that, whatever the applied pressure, the average grain size after SPS is close to $20 \mathrm{~nm}$, as shown for 300 and $500 \mathrm{MPa}$ in Figure $2 \mathrm{a}-\mathrm{d}$, respectively. The postannealing at $700{ }^{\circ} \mathrm{C}$ performed to release residual stress arising from SPS process allows reaching a density value as high as $93 \%$ (pressure 400-600 MPa) without an increase of the average grain size which remains lower than $20 \mathrm{~nm}$.

No extra phase was observed on the X-ray diffraction (XRD) pattern after SPS sintering. The width of the peaks remained similar between the raw powder (before SPS), the ceramic and the ceramic annealed at $700{ }^{\circ} \mathrm{C}$, confi rming the absence of grain growth whatever the applied pressure. No splitting of the pseudo cubic (200) into tetragonal (200) and (002) refl ections appeared after sintering suggesting an average cubic structure in both the initial powder and the SPS ceramics (Figure $2 \mathrm{e}$ ). SPS ceramics were then annealed at $1100{ }^{\circ} \mathrm{C}$ in order to induce grain coarsening and then to probe the impact of grain growth on both structural and dielectric features. After the thermal treatment and whatever the pressure initially applied during SPS, the grain size within the ceramics reaches $100 \mathrm{~nm}$ as shown by HRSEM ( Figure 3 ). 


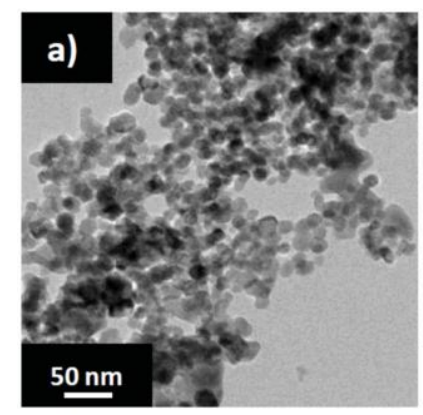

c)

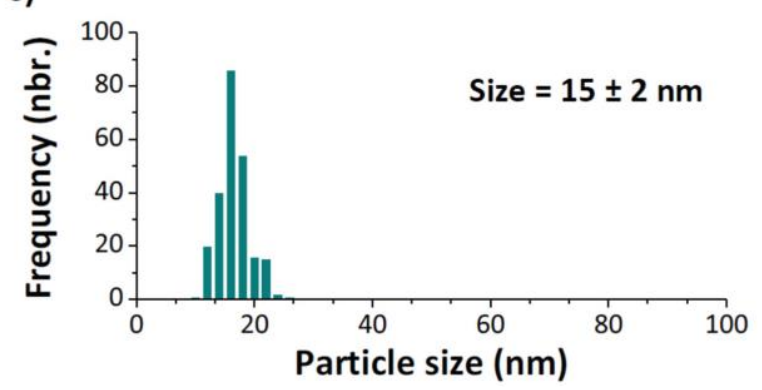

Figure 1. a) Transmission electron microscopy (TEM) image of

$\mathrm{Ba} 0.6 \mathrm{Sr} 0.4 \mathrm{TiO}$ 3 nanoparticles synthesized by supercritical fl uids and

b) high resolution transmission electron microscopy (HRTEM) image

showing the high crystallinity of the particles. c) Crystal size distribution.
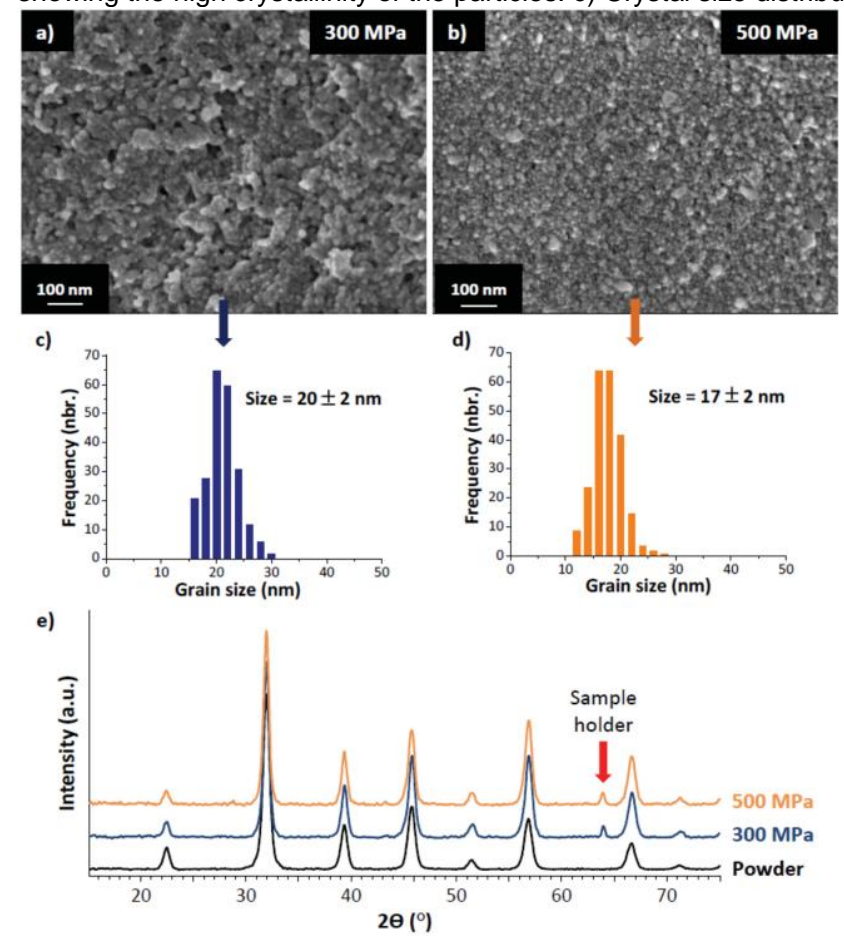

Figure 2. a,b) HRSEM images of the fracture surface of the BST ceramics processed by spark plasma sintering at $750{ }^{\circ} \mathrm{C}$ under uniaxial pressure of 300 and $500 \mathrm{MPa}$, respectively; c,d) the corresponding grain size distributions; and e) X-ray diffraction patterns of BST nanopowder and BST ceramics sintered under uniaxial pressures of 300 and $500 \mathrm{MPa}$. 


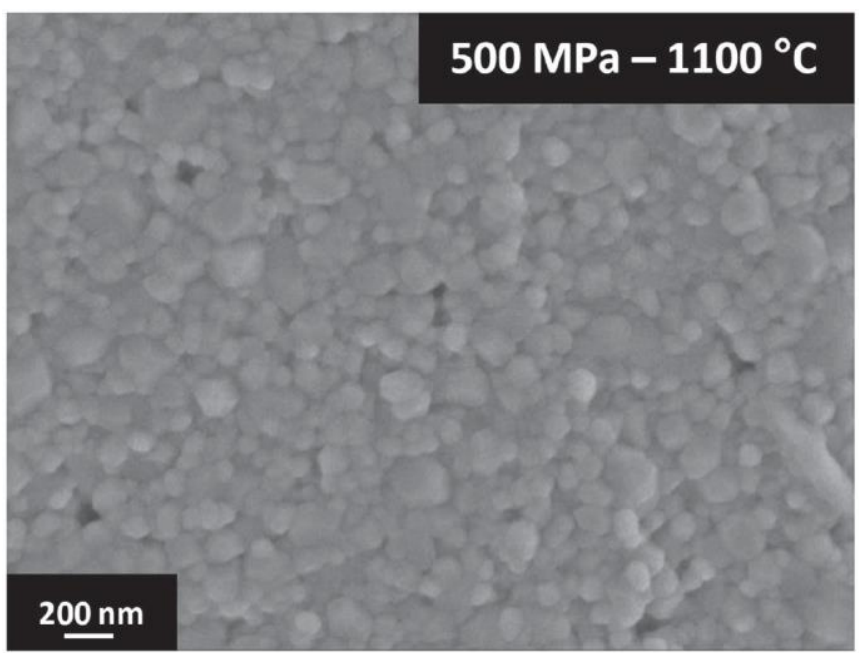

Figure 3. HRSEM image of the fracture surface of the BST ceramic processed at $500 \mathrm{MPa}$ after annealing at $1100^{\circ} \mathrm{C}$.

\subsection{Short Range Structure Investigation by Raman Spectroscopy}

As shown in several reports from literature, the local structure in nanosized ferroelectrics does not possess as high symmetry as XRD measurements may suggest (Figure 2 e). [ 6,11,31-33 ] To get better insight into the structure at the unit cell level (i.e., short range) Raman spectroscopy offers the advantage to be accurate either on powder or ceramic and is very sensitive to the local dynamic symmetry with a coherence length lower than $2 \mathrm{~nm}$. The infl uence of pressure applied during SPS on the local structure will be discussed here considering the evolution of Raman spectra within the relevant frequency range involving oxygen octahedral vibrations. Soft Raman modes related to intrinsic size effect on ferroelectricity occur at frequencies lower than the ones investigated here and thus will not be considered in our discussion. The comparison of spectra between the powder and the ceramics sintered at different pressures highlights three main differences ( Figure 4 a):

- The peak close to $180 \mathrm{~cm} \quad 1$ associated to a marked negative dip is observed in the powder but becomes more pronounced in the ceramics. This mode was already reported in literature and is ascribed to a strain-induced orthorhombic phase, which can be locally stabilized at room temperature in a nanosized ferroelectric. [ 6,34] Such an increase of the polar character at a very local scale is supported by the intensity increase of the A 1 (TO) peak close to $230 \mathrm{~cm} 1$ which becomes more prominent after the SPS step. The overall broad spectral signature can be associated with an overall pseudo cubic character. - The only shift observed in the spectra occurs at the $730 \mathrm{~cm} \quad 1$ mode. This mode is attributed to a combination of A 1 (LO) and $\mathrm{E}(\mathrm{LO})$ modes that consist of motions of the Ti and O1 (apical oxygen sites) against the $\mathrm{O} 2$ and $\mathrm{O} 3$ planar oxygens in the $\mathrm{TiO} 6$ octahedron. Hence, such a shift is related to an increase of the unit cell distortion (orthorhombic or tetragonal). [ 35 ] The Raman peak at $810 \mathrm{~cm} \quad 1$ related to the presence of structural $\mathrm{OH}$ defects and present in the powder is released in the ceramic thus demonstrating the stabilization of the long range tetragonal structure.

- The Raman investigation performed on the ceramics annealed at $1100{ }^{\circ} \mathrm{C}$ (grain size close to $100 \mathrm{~nm}$ ) revealed noticeable changes: the shift of the mode at 500-600 cm 1 and the disappearance of the peak at $180 \mathrm{~cm} 1$. These features were similarly observed for the ceramics sintered under 300 and $600 \mathrm{MPa}$. 
The overall spectral signature resembles the traditional Raman spectrum of pseudo cubic BST (Figure 4 b,c). [36 ]
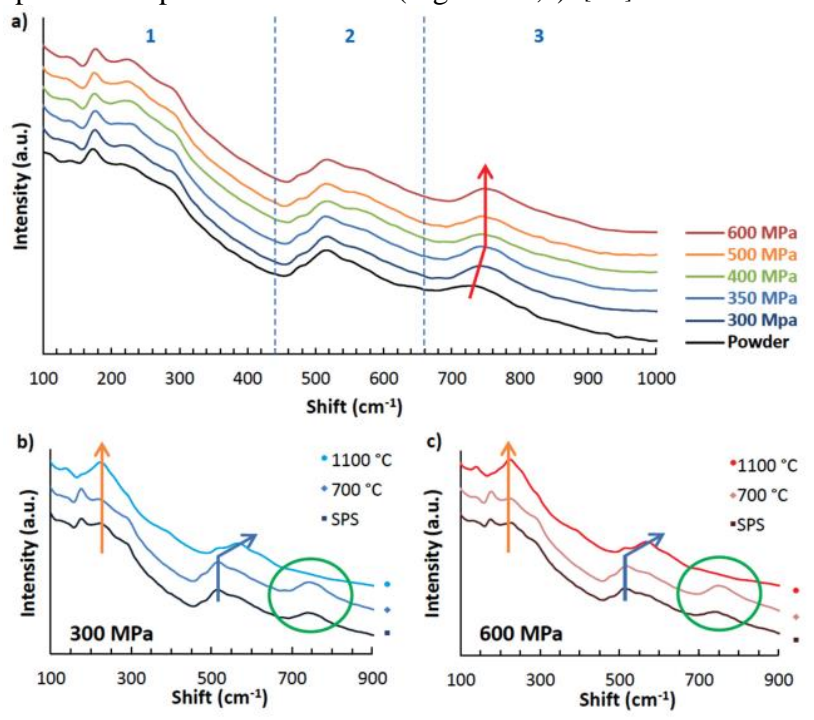

Figure 4. Raman spectra of a) BST nanopowder and SPS ceramics processed at different pressures from 300 up to $600 \mathrm{MPa}$ and b,c) ceramics processed

by SPS at 300 and $600 \mathrm{MPa}$, respectively, and annealed at 700 and $1100{ }^{\circ} \mathrm{C}$ in each case. Arrows indicate the shift observed in different modes of the spectra.

\subsection{Dielectric Characterizations}

The dielectric measurements performed on the SPS nanostructured ceramics clearly show the existence of a phase transition with a maximum of permittivity as a function of temperature whatever the applied pressure during SPS ( Figure 5 a). The Curie temperature $(T \mathrm{C})$ of the ceramic obtained at $300 \mathrm{MPa}$ is estimated close to $180 \mathrm{~K}$. Increasing pressure during sintering led to two noticeable effects: (i) a decrease of the permittivity (despite of the increase in ceramic density) and (ii) a variation of the Curie temperature associated with a broadening of the transition maximum. Reporting the Curie temperature as a function of the applied pressure during sintering evidences unambiguously an increase of the transition temperature from $\mathrm{H} 180$ to $\mathrm{H} 207 \mathrm{~K}$ when the pressure increases from 300 to $400 \mathrm{MPa}$, respectively, and then $T$ c remains stable in a second regime from 400 to $600 \mathrm{MPa}$ (Figure $5 \mathrm{~b}$ ). In parallel, the maximum of permittivity at $T$ C can be plotted as a function of the applied pressure (Figure $5 \mathrm{c}$ ). Similarly to the $T$ c evolution as a function of the pressure, two regimes can be distinguished, the $\sum$ max values decrease for a SPS pressure up to $400 \mathrm{MPa}$, and then stabilize with a further increase of pressure up to $600 \mathrm{MPa}$. 

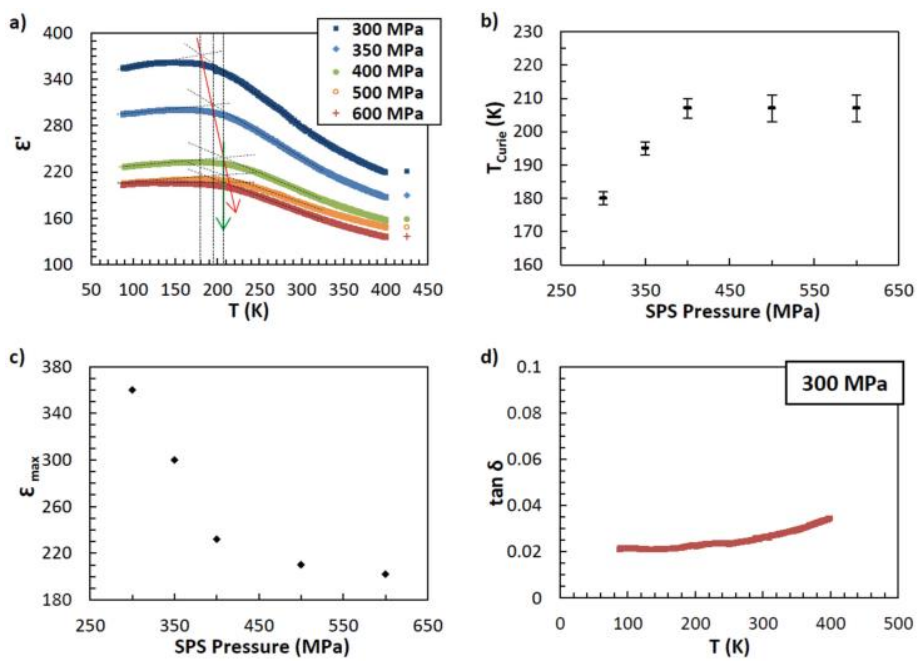

Figure 5. a) Permittivity temperature dependence ( $f=10 \mathrm{kHz}$ ) of ceramics processed at different applied pressures, b) evolution of the Curie temperature as a function of the pressure applied during sintering, c) evolution of the maximum of permittivity as a function of the pressure applied during sintering and d) temperature dependence of the dielectric losses for the ceramic sintered under $300 \mathrm{MPa}$.

The dielectric losses stabilization in the overall temperature range can be highlighted (Figure $5 \mathrm{~d}$ ). Such values ranging between 0.02 and 0.04 are quite low considering the high density of grain boundaries and confi rm that the macroscopic properties are not mainly dominated by extrinsic contributions such as charged defects at the grain boundaries. This is in good agreement with the low permittivity, which is not artifi cially raised by such extrinsic contributions.

The grain growth resulting from the annealing of the SPS ceramics led to signifi cant changes on the dielectric properties: an increase of the permittivity, a narrower paraelectric-ferroelectric phase transition and a shift of the $T \mathrm{C}$ toward a higher and stable value $(265 \mathrm{~K})$ whatever the applied SPS pressure

\section{( Figure 6 ).}

\section{Discussion}

The fi rst signifi cant result lies in the processing of well-densifi ed nanostructured BST64 ceramics with $20 \mathrm{~nm}$ grains. Using both highly crystallized and pure initial BST nano powders and specifi c SPS conditions (air atmosphere and high pressure) allowed avoiding thermal treatments at high temperature leading to grain growth. Raman investigation revealed an increase of the polar character at a very local scale in the nanostructured ceramic compared to the nanopowder. The ferroelectric transition was evidenced close to $180 \mathrm{~K}$. This result allowed to complete with good agreement the study of Hornebecq et al. reporting the $T$ c evolution of $\mathrm{Ba} 0.6 \mathrm{Sr}_{0.4} \mathrm{TiO}_{3}$ particles as a function of their grain size. [16] The permittivity and losses remained low in spite of the high density of grain boundaries, therefore discarding any signifi cant extrinsic contribution of charged defects. [37,38]

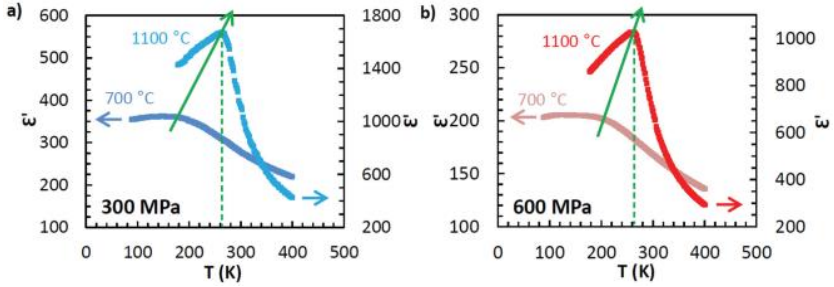

Figure 6. Permittivity temperature dependences ( $f=10 \mathrm{kHz}$ ) of ceramics processed by SPS at a) $300 \mathrm{MPa}$ and b) $600 \mathrm{MPa}$ and annealed at 700 and $1100^{\circ} \mathrm{C}$ in each case. Arrows indicate the increase of the Curie temperature after annealing at high temperature. 
Grain size and processing effects on the properties were investigated at different scales through microstructural, Raman, and dielectric studies. The increase of the Curie temperature when the SPS pressure increased was unexpected and cannot be linked to an increase of grain size considering both the microstructural analysis and the concomitant decrease in permittivity. Interestingly, such a decrease in permittivity with increasing sintering pressure occurs despite the increase of the ceramic density. As a result, the evolution of the dielectric parameters fully discards any grain size effect. As a matter of fact, such an increase of the Curie temperature can be explained considering the local structure and can be correlated to the permittivity evolution. In view of the high surface ratio of the $20 \mathrm{~nm}$ grains, the core-shell model consisting in the coexistence of a cubic surface layer and a tetragonal grain core can be considered. [11] It can thus be assumed that in the fi rst regime (i.e., pressure up to $400 \mathrm{MPa}$ ), the applied stress during sintering acts as a competitive external stress opposed to the mechanical surface stress due to size effect acting as an hydrostatic pressure. [ 39] To support this assumption and to show the link between external stress and stress at the grain scale, stress modeling was carried out at the vicinity of the contact point between two barium titanate half-spheres of $20 \mathrm{~nm}$ in diameter. The stress was evaluated as a function of the stress applied on the equatorial surfaces ( Figure 7 ). The Von Mises equivalent stress was calculated by fi nite element modeling using Comsol Multiphysics. The used mechanical properties were those of bulk BaTiO 3 (Young modulus $67 \mathrm{GPa}$ and Poisson coeffi cient 0.5 ). An interpenetration of $0.1 \mathrm{~nm}$ of the two half spheres was envisaged to ensure good contact between them and a refi ned mesh was used at the vicinity of the contact point. The stress values reported in Figure 7 correspond to average values of three points taken at the vicinity of the contact point. The results show that when applying an external load of 500 $\mathrm{MPa}$ on $20 \mathrm{~nm}$ grains, the resulting stress at the contact point reaches $20 \mathrm{GPa}$. Even taking into account a "dilution effect" due to the polycristallinity of the material, the pressure at the grain scale is high enough to compete with the surface stress arising from nanometer grain size. The lateral stress was also evaluated considering as limit conditions the prescribed displacement (in the $x-, y-$, and $z$-axes) of the equatorial external points of the sphere. The obtained value is much lower, i.e., $130 \mathrm{MPa}$. As a result, the paraelectric shell contribution is decreased by the external applied pressure, thus leading to an increase of $T \mathrm{C}$. The internal lateral strain remains and forces the polarization along the direction of the applied pressure, which is also the direction of the applied electric fi eld. The decrease of the permittivity is consistent with an increase of the lattice distortion, similar to what happens in $\mathrm{Pb}$-doped barium titanate. [ 40 ] At pressure values higher than $400 \mathrm{MPa}$, the plateau could refl ect a balance reached between the external stress and the internal surface stress and a further increase of the pressure does not affect anymore both the permittivity and $T \mathrm{C}$ values. This model is supported by the Raman measurements, which show a shift of the $730 \mathrm{~cm} 1$ mode to higher wavenumber only up to 400 $\mathrm{MPa}$. This blueshift occurs in a breathing-type mode, which is particularly sensitive to isostatic pressure. It refl ects a higher lattice distortion due to strain increase in the ceramic and is in good agreement with both an increase of the Curie temperature and a decrease of the permittivity. The core-shell confi guration in $20 \mathrm{~nm}$ grain size particles could also be described in terms of elasticity and plastic deformation regime. A maximum of bulk 
modulus at a specifi c size of $15 \mathrm{~nm}$ was reported in $\mathrm{TiO} 2$ nanoparticles.

[41] The stabilization of the dielectric parameters when

increasing the pressure beyond $400 \mathrm{MPa}$ should be discussed

in regard to a limit of elasticity reached at a pressure threshold.

Deeper investigations to probe nanoscale structural defects

such as dislocations are required in order to link the lattice

strain on the surface of the nanoparticles with their mechanical

behavior.

The ferroelectric domain confi guration is also affected

in such ultrafi ne ferroelectric grains. [ 11,42 ] This can be seen

through the softening of the maximum of

losses, occurring in the vicinity of the transition

temperature in bulk BST (Figure $5 \mathrm{c}$ ).

Grains of $20 \mathrm{~nm}$ size are not able to develop

$90^{\circ}$ ferroelastic-ferroelectric domains

required to minimize the elastic energy

resulting from the deformation of the unit

cell at $T \mathrm{C}$. As a result, the domain walls present

within the grains are those contributing

only to polarization $\left(180^{\circ}\right.$ domains). Considering

the very small size of the grains, this

contribution is expected to be lower than in

micrometer grain size ceramics, thus minimizing

losses. This aspect suggests that a

judicious grain size (and thus domain) engineering

could lead to fi ne tuning or minimization

of losses which can be of considerable

practical interest in many applications.
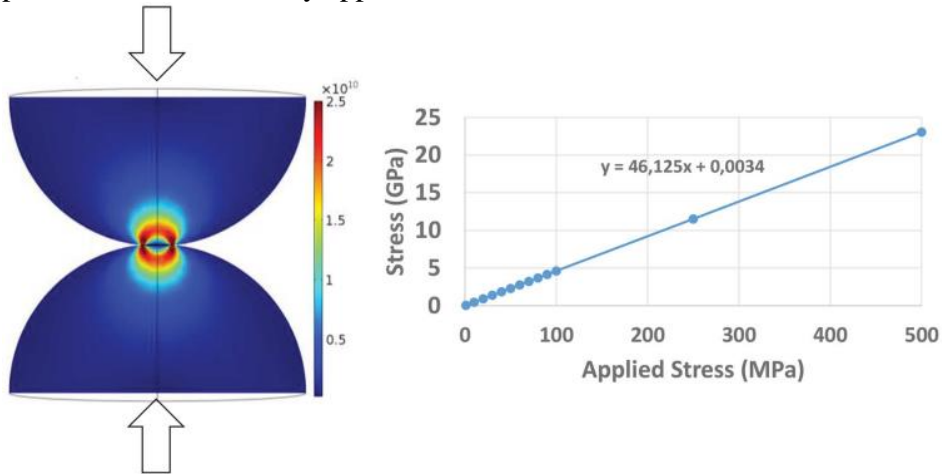

Figure 7. Stress at the vicinity of the contact point between two barium titanate half-spheres of $20 \mathrm{~nm}$ in diameter as a function of the stress applied on their equatorial surfaces, evaluated by fi nite element modeling.

To summarize, the main effect of SPS

performed under high pressure is to

increase the mismatch strain existing between the inner core and the surface of the grains (closer contact between grains

in ceramics compared to the powder and high external pressure applied during sintering). The contributions of both internal and external stress effects in the nanostructured ceramics with $20 \mathrm{~nm}$ grain size lead to a short range dominated structure with a higher lattice distortion than in the initial powder.

After the thermal treatment at $1100{ }^{\circ} \mathrm{C}$ and whatever the pressure initially applied during SPS, the grain size within the ceramic reaches $100 \mathrm{~nm}$ as shown by HRSEM (Figure 3 ). It is expected that through this grain growth any strain present in the samples produced by SPS would be released. Interestingly, the $T \mathrm{C}$ of the annealed ceramics merges in the same value $(265 \mathrm{~K})$ confi rming that the change of $T$ C observed in 
the $20 \mathrm{~nm}$ grain size ceramics is directly related to the external stress induced by the SPS pressure. Hence, the pressure applied during SPS can affect the structural distortion below a critical grain size corresponding to a surface strain high enough to be sensitive to such an additional external stress. When the surface strain is relaxed through the grain growth, the applied external pressure has no more impact on the Curie temperature. The Raman investigation also evidences a change of the local structure after annealing. The observed shift of the mode at 500-600 cm 1 refl ects an evolution towards a long range order (pseudo cubic structure). In addition, the peak at $180 \mathrm{~cm}-1$ related to size effect disappears. At $100 \mathrm{~nm}$ grain size, the strain arising from the surface effect is no more predominant. The remaining of some intrinsic residual strain cannot be discarded; however, the corresponding effects occur only at the very local scale and are not distinguishable in the observed Raman spectra.

\section{Conclusion}

Advanced synthesis of ferroelectric nanoparticles and their high-pressure densifi cation by SPS under air led to a consistent evaluation of their macroscopic and local structure.

The fi rst outcome is that ferroelectricity is preserved in dense ceramics of $20 \mathrm{~nm}$ grain size while the transition temperature decreased. We achieved an improved control of the dielectric permittivity and losses which were not altered by spurious defects and grain boundaries. This enabled a reliable evaluation of the external stress effect on the transition temperature. Increasing the uniaxial pressure during the sintering step up to several hundreds of $\mathrm{MPa}$, we were able to break the paraelectric shell, impacting the ferroelectric core of each individual grain, and thus restoring ferroelectricity through an increase of the transition temperature. This was ascribed to the hardening of the oxygen octahedra breathing mode which is primarily sensitive to the strain at the unit cell level. Our conclusions were supported by fi nite element modeling simulations which highlight the very high stress generated at the grain scale. These results open new insights to explore the pressure effect during SPS sintering on the intrinsic properties of polycrystalline nanomaterials when focusing on a grain size regime small enough to become particularly sensitive to an external stress.

\section{Experimental Section}

The starting chemicals used were barium isopropoxide (99.9\%, Aldrich, CAS: 24363-37-9), strontium isopropoxide (99.9\%, Aldrich, CAS: 88863$33-6)$, titanium isopropoxide ( $\varepsilon 98 \%$, Strem chemicals, CAS: $546-68-$ 9 ), and ethanol ( $899.8 \%$, Aldrich, CAS: $64-17-5)$. The entire BST solid solution can be processed using supercritical fl uids technology simply by adjusting the precursor ratio to the expected composition prior injection of the mixture in the reactor. [24,25] The tubular reactor used in the setup had an overall length of $24 \mathrm{~m}$ in which the residence time was set to $50 \mathrm{~s}$. The temperature and the pressure within the reactor were $400^{\circ} \mathrm{C}$ and $23 \mathrm{MPa}$, respectively. The molar fraction of ethanol in water was set at 0.29 , leading to a mixture with a supercritical point at $T \mathrm{C}=305^{\circ} \mathrm{C}$ and $13 \delta P_{\mathrm{c}} \delta 17 \mathrm{MPa}$, which are lower than the ones of pure water $\left(T \mathrm{C}=374^{\circ} \mathrm{C}\right.$ and $P_{\mathrm{c}}=22.1 \mathrm{MPa}$ ). The solvent ratio (ethanol/water) is a key parameter to improve the crystallinity of the nanoparticles. Spark plasma sintering was performed using a Dr Sinter 2080 SPS device (SPS Syntex Inc., Tokyo Japan) of the Plateforme Nationale CNRS de Frittage Flash located at Université Toulouse Paul Sabatier III. BST powder (without any sintering aids) was loaded onto an $8 \mathrm{~mm}$ inner diameter cylindrical tungsten carbide die covered with a graphite foil. The sintering was performed under air at $750^{\circ} \mathrm{C}$, holding time $2 \mathrm{~min}$, pulse sequence 12-2 (on-off), and an uniaxial pressure in the range of $300 \mathrm{MPa}$ up to $600 \mathrm{MPa}$ was applied. Considering the high surface reactivity of the nanopowders, 
the pressure was applied at the beginning of the cycle at room temperature in order to avoid grain growth. The pressure was then gradually removed before cooling to minimize strain within the sample. An annealing under air at a temperature lower than the sintering temperature $\left(700^{\circ} \mathrm{C}\right.$ during $\left.10 \mathrm{~h}\right)$ was performed in order to release residual stress arising from SPS process and also to remove any contribution of conductivity which can occur due to surface contamination resulting from the use of the carbon foil and from the strong reactivity of the nanoparticles.

In order to induce grain growth, a post thermal annealing treatment was performed in air at $1100{ }^{\circ} \mathrm{C}$ during $10 \mathrm{~h}$.

Diffraction patterns were recorded at room temperature with a PANalytical X'Pert MPD-PRO powder diffractometer equipped with a germanium monochromator. The diffraction of the $\mathrm{Cu} \mathrm{K}<1$ radiation at $L_{1}=1.54060 \AA$ generated at $45 \mathrm{kV}$ and $40 \mathrm{~mA}$ is only observed.

TEM was performed using a JEOL $2200 \mathrm{FS}$ with an accelerating voltage of $200 \mathrm{kV}$ and equipped with a high resolution camera. The resolution is $0.23 \mathrm{~nm}$. The Digital Micrograph (GATAN) software was used to record the pictures. HRSEM maps were obtained using a scanning electron microscope (SEM) JEOL JSM 7800F Prime, at the Unité Mixte de Service (UMS) Raymond Castaing, Toulouse. The smallest grains $(<10 \mathrm{~nm})$ were evidenced by using a low acceleration voltage $(2 \mathrm{kV})$ and without any metallization of the sample.

The Raman spectrometer used was a Thermo Scientifi c DXR microscope with a $532 \mathrm{~nm}$ wavelength excitation laser operating at $8 \mathrm{~mW}$ output power. Focusing was realized with a confocal microscope equipped with a 10. objective, leading to a surface analysis area of $3.5 \mu \mathrm{m}$ 2. The resolution was $3 \mathrm{~cm} \quad 1$ over a window from 15 to $3550 \mathrm{~cm} 1$. The dielectric measurements were carried out with an automatic

Wayne-Kerr 6425 impedance bench developed at ICMCB in a frequency range from $100 \mathrm{~Hz}$ to $200 \mathrm{kHz}$. Gold electrodes were deposited on two parallel faces of the ceramic and the real and imaginary contributions of the permittivity, $\sum 2$ and $\sum 3$, were respectively determined from the measured capacitance $(C)$ and losses $\left(\tan { }^{\mathrm{T} M}\right.$ ).

\section{Acknowledgements}

This work had been made possible by the fi nancial support of the ANR project ARCHIFUN (ANR-12-BS08-009), the Région Aquitaine and the International Doctoral School in Functional Materials (IDS FunMAT).

[1] S. Shukla, S. Seal, R. Vij, S. Bandyopadhyay, Z. Rahman, Nano Lett. $2002,2,989$.

[2] M. Diapiaggi , F. Maglia , I. Tredici , B. Maroni , U. Anselmi-Tamburini , J. Phys. Chem. Solid 2010, 71, 1038 .

[3] A. Weibel, R. Bouchet, R. Denoyel , P. Knaught, J. Eur. Ceram. Soc. $2011,27,2641$.

[4] J. M. McHale , A. Auroux , A. J. Perotta , A. Navrotsky , Science 1997 , 277,788

[5] F. Maglia , M. Dapiaggi , I. Tredici , U. Anselmi-Tamburini , Nanosci.

Nanotechnol. Lett. 2012 , 4, 205.

[6] M. H. Frey , D. A. Payne, Phys. Rev. B 1996 , 54, 3158

[7] S. Lin , T. Lü , C. Jin , X. Wang, Phys. Rev. B 2006, 74, 134115.

[8] M. B. Smith , K. Page, T. Siegrist , P. L. Redmond, E. C. Walter,

R. Seshadri , L. E. Brus , M. L. Steigerwald , J. Am. Chem. Soc. 2008 , 130,6955 .

[9] V. Petkov , M. Gateshki , M. Niederberger , Y. Ren , Chem. Mater. 2006 , 18,814 .

[10] X. Wang , X. Deng , H. Wen , L. Li , Appl. Phys. Lett. 2010 , 89, 162913.

[11] T. Hoshina, J. Ceram. Soc. Jpn. 2013, 121, 156.

[12] Z. Zhao , V. Buscaglia, M. Viviani , M. Buscaglia , L. Mitoseriu

A. Testino, M. Nygren, M. Johnsson , P. Nanni , Phys. Rev. B 2004 ,

70,024107 .

[13] M. C. Blanco Lopez , B. Rand , F. L. Riley , J. Eur Ceram. Soc. 1997 , 17,81 .

[14] S. Wada , T. Suzuki , T. Noma , J. Ceram. Soc. Jpn. 1996, 104, 383.

[15] S. W. Lu, B. I. Lee , Z. L. Wang , W. D. Samuels , J. Cryst. Growth 2000 219,269 .

[16] V. Hornebecq , C. Huber, M. Maglione , M. Antonietti , C. Elissalde , Adv. Funct. Mater. $2004,14,899$.

[17] T. Hungria, M. Alguero, A. B. Hungria, A. Castro, Chem. Mater.

$2005,17,6205$. 
[18] A. F. Rabuffetti , R. L. Brutchey, Dalton Trans. 2014 , 43, 14499.

[19] Y. Gao , V. V. Shvartsman , D. Gautam , M. Winterer , D. C. Lupascu , J. Am. Ceram. Soc. 2014, 97, 2139 .

[20] J. Becker , P. Hald , M. Bremholm , J. S. Pedersen , J. Chevallier, S. B. Iversen , B. B. Iversen, ACS Nano 2008 , 2, 1058.

[21] C. Bousquet , C. Elissalde , C. Aymonier , M. Maglione , F. Cansell , J. M. Heintz , J. Eur. Ceram. Soc. 2008, $28,223$.

[22] Y. Roig , S. Marre , T. Cardinal , C. Aymonier, Angew. Chem. Int. Ed.

2011, 50, 12071 .

[23] G. Philippot , C. Elissalde , M. Maglione , C. Aymonier , Adv. Powder Technol. $2014,25,1415$.

[24] H. Reverón , C. Elissalde , C. Aymonier , C. Bousquet , M. Maglione , F. Cansell , Nanotechnology $2006,17,3527$.

[25] G. Philippot, K. M. Jensen, M. Christensen, C. Elissalde , M. Maglione, B. Iversen, C. Aymonier , J. Supercrit. Fluids 2014, 87 , 111 .

[26] R. Chaim , M. Levin , A. Shlayer, C. Estournès, Adv. Appl. Ceram.

$2008,27,159$.

[27] F. Maglia , I. G. Tredici , U. Anselmi-Tamburini , J. Eur. Ceram. Soc.

2013, 33, 1045 .

[28] U. Anselmi-Tamburini , J. E. Garay , Z. A. Munir , Scr. Mater. 2006 , 54 , 823 .

[29] Z. Valdez-Nava , C. Tenailleau , S. Guillemet-Fritsch , N. El Horr , T. Lebey, P. Dufour, B. Durand, J.-Y. Chane-Ching , J. Phys. Chem. Sol. $2011,72,17$.

[30] U.-C. Chung, C. Elissalde , C. Estournès, M. Maglione, Appl. Phys. Lett. $2009,94,072903$.

[31] H.-W. Lee, S. Moon , C. H. Choi , D. K. Kim , J. Am. Ceram. Soc. 2012 , 95,2429 .

[32] H. Zhang , X. Wang , Z. Tian , C. Zhong , Y. Zhang , C. Sun , L. Li , J. Am. Ceram. Soc. 2011, 94, 3220 .

[33] Y. Li , Z. Liao , F. Fang , X. Wang , L. Li , J. Zhu , Appl. Phys. Lett. 2014 , 105,182901 .

[34] A. Gajovic' , J. V. Pleština , K. Žagar , M. Plodinec , S. Šturm , M. C`eh , J. Raman Spectrosc. 2013, 44, 412 .

[35] T. Zhang , J. Mater. Sci.: Mater. Electron. 2009 , 20 , S190 .

[36] S. Y. Wang, B. L. Cheng, C. Wang, S. Y. Dai , K. J. Jin , Y. L. Zhou, H. B. Lu , Z. H. Chen, G. Z. Yang , J. Appl. Phys. 2006 , 99, 013504 .

[37] V. Buscaglia , M. T. Buscaglia, M. Viviani , L. Mitoseriu , P. Nanni , V. Trefi letti , P. Piaggio, I. Gregora, T. Ostapchuk, J. Pokorny, J. Petzelt , J. Eur. Ceram. Soc. $2006,26,2889$.

[38] H. Zhang, X. Deng , T. Li , W. Zhang, R. Chen, W. Tian , J. Li , X. Wang , L. Li , Appl. Phys. Lett. 2010, 97, 162913.

[39] L. Mitoseriu , V. Tura , C. Papusoi , T. Osaka, M. Okuyama, Ferroelectrics $1999,223,99$.

[40] H. J. Martin , Die Ferroelektrika, Akademische Verlagsgesellschaft , Geest\&Portig, Leipzig 1964 .

[41] B. Chen, H. Zhang, K. A. Dunphy-Guzman , D. Spagnoli ,

M. B. Kruger, D. V. S. Muthu, M. Kunz, S. Fakra , J. Z. Hu , Q. Z. Gou, J. F. Banfi eld , Phys. Rev. B 2009, 79, 125406.

[42] D. Ghosh , A. Sakata , J. Carter , P. A. Thomas, H. Han , J. C. Nino, J. L. Jones , Adv. Funct. Mater. 2014 , $24,885$. 